\title{
Educação de jovens e adultos e educação especial: a (re) invenção da articulação necessária entre as áreas
}

\author{
Youth and adult education and special education: the (re)invention of \\ the necessary articulation between these areas
}

Clarissa Haas*

Universidade Federal do Rio Grande do Sul

Resumo Este estudo exploratório propõe a aproximação entre a Educação Especial e a Educação de Jovens e Adultos, analisando as contribuições que os direcionamentos legais e políticos nacionais trazem acerca da Educação Especial na perspectiva da Educação Inclusiva. As publicações dos Fóruns EJA e a produção acadêmica têm propiciado o diálogo entre as duas áreas. A imersão teórica e crítica nos "lugares" considerados legítimos para que esse diálogo aconteça foi feita a partir da premissa da EJA no ensino comum, como espaço escolar potencializador, para que os jovens e adultos com deficiência desenvolvam seus modos singulares de aprender. A investigação apontou a timidez de estudos com esse viés e a necessidade de ampliar a discussão sobre o Atendimento Educacional Especializado para os jovens e adultos com deficiência.

PALAVRAS-CHAVE: Educação de Jovens e Adultos; Educação Especial; Jovem e adulto com deficiência.

Abstract This exploratory study proposes the approximation between Youth and Adult Education and Special Education, by analyzing the contributions provided by the national lawful and political guidance about Special Education considering the Inclusion Education perspective. The publications from the Youth and Adult Education Forums and the academic production have brought some dialogue between both areas. The theoretical and critical immersion in "places" considered as legitimate to make this dialogue possible from the premise of Youth and Adult Education being in the regular school as a potentialized space for impaired youths and adults to develop their singular ways of learning. This investigation has pointed out the scarcity of studies within this focus and the need for widening the discussion about the Specialized Education to impaired youths and adults.

KEYWORDS: Youth and Adult Education; Special Education; Impaired youths and adults. 


\section{Jovens e adultos com deficiência nos bancos escolares da}

A introdução da discussão, a partir de alguns apontamentos à Educação de Jovens e Adultos, tem o intuito de ampliar o foco para além dos sujeitos da Educação Especial que, atualmente, são demandantes dessa modalidade de ensino, e de voltarse à cultura pedagógica como um todo. De certa forma, esse anúncio já foi feito pelo estudioso francês Edouard Séguin (um dos precursores da área da Educação Especial), em meados do século XIX, mas continua contemporâneo:

As fórmulas da Educação atualmente aceitas são ridículas e odiosas; ridículas quando atrofiam nas massas as faculdades e as funções mais nobres necessárias à vida. Portanto, a propósito da idiotia ${ }^{1}$, trata-se apenas de propor novamente o problema da Educação. (SÉGUIN, 1997, p. 242 apud TEZZARI e BAPTISTA, 2011, p. 24).

Assim, reforça-se o olhar à reinvenção das práticas pedagógicas em consonância com as singularidades dos seus sujeitos e à inclusão do jovem e adulto com deficiência no ensino comum, a partir da modalidade da EJA, mediante o entendimento de que esse espaço escolar pode constituir-se como lugar potente e legítimo para atender as necessidades específicas dessa faixa etária e como meio de prover continuidade ao desenvolvimento humano e social das pessoas com deficiência.

Para o enfrentamento do debate disparado pela necessidade de articulação entre as áreas da Educação de Jovens e Adultos e da Educação Especial, propõem-se como instrumentos de investigação e análise: a reflexão sobre os dispositivos legais e ordenadores no contexto nacional da Educação Especial na perspectiva da educação inclusiva; a produção sistematizada pelos encontros nacionais e regionais realizados pelo Fórum EJA; as pesquisas realizadas na última década (2000-2012), nos principais bancos de dados de pesquisas acadêmicas (Banco de Teses e Dissertações da CAPES; Grupos de Trabalhos da Educação Especial (GT-07) e da EJA (GT-18), da Associação Nacional de Pesquisas em Educação (ANPEd).

Arroyo (2005) sintetiza como indicativos históricos responsáveis pela reconfiguração da Educação de Jovens e Adultos como direito inalienável: a criação, a partir de 2004, de um espaço institucional no Ministério de Educação (MEC), especificamente na Secretaria de Educação Continuada, Alfabetização, Diversidade e Inclusão $(\mathrm{SECADI})^{2}$, para a promoção de políticas públicas direcionadas à EJA; a discussão com o Fundo de Manutenção da Educação Básica (Fundeb); a criação dos Fóruns de EJA como um espaço de discussão promissor e articulador de um novo compromisso entre o estado e a sociedade; o investimento na formação de profissionais para a EJA; a ampliação de pesquisas e da produção teórica na área.

$\mathrm{Na}$ análise do contexto histórico brasileiro acerca da formalização e do desenvolvimento de políticas públicas para a Educação Especial e para a EJA, nitidamente se observam trajetórias que convergem no que diz respeito à tradição de descaso dirigido a essas duas áreas. Isso representou, para os sujeitos da Educação Especial, a legitimação de espaços externos à Educação, em geral, de cunho assistencialista e medicalizante, em detrimento do acesso aos saberes pedagógicos. Já para a EJA, sig- 
nificou a ampliação de ações de alfabetização de adultos em espaços de iniciativa não governamental ou filantrópica, com caráter compensatório.

É possível perceber que, para ambos os grupos de sujeitos - pessoas com deficiência; jovens e adultos em defasagem escolar -, as discussões sobre o direito à educação, por muito tempo, ignoraram ou minimizaram um debate pedagógico e, com isso, desconsideraram o fato de eles constituírem demanda real do campo da Educação e de necessitarem de saberes e de fazeres específicos às suas peculiaridades.

A EJA, assim como a Educação Especial, vive um momento de reconfiguração de suas políticas, como responsabilidade pública do Estado, o que repercute no contexto escolar, com a aproximação dessas modalidades, ou seja, com o ingresso cada vez mais numeroso dos alunos, jovens e adultos com deficiência, nos bancos escolares da EJA.

Em relação às demandas de sujeitos da EJA e da Educação Especial, também é possível reconhecer concepções que se entrelaçam, de forma que as pessoas com deficiência e os jovens e adultos em processo de escolarização atravessam o contexto atual com a mesma necessidade: a de serem reconhecidos além de suas carências, além de uma visibilidade dada por suas vulnerabilidades ou pela negação de sua condição como sujeitos históricos. Embora o caráter de suplência não seja mais a tônica das políticas públicas, este ainda sobrevive no imaginário social e nas práticas pedagógicas de muitas escolas, em que o olhar aos demandantes da EJA recai sobre a falta: falta de conhecimentos acadêmicos e atitudinais; falta de experiência; falta de conhecimentos adquiridos na convivência e no trabalho, sendo comum o discurso de "preencher as lacunas" de uma escolarização anterior ou da ausência de um percurso escolar. Essa visão se sustenta na incapacidade do aluno jovem e adulto, cristalizando-se, ainda mais, com a identificação de jovem e adulto "com deficiência". Dessa forma, a incapacidade já existe "a priori", independentemente de quem seja o jovem e adulto e/ou o jovem e adulto com deficiência que vai ingressar na EJA, pois a modalidade por si só passa a projetar um "status" depreciativo do sujeito.

As pesquisas sobre Educação de Jovens e Adultos no Brasil, até os anos 1990, contribuíram para homogeneizar os sujeitos de aprendizagem da EJA, a partir do enraizamento das representações sociais do analfabeto pobre, do jovem urbano pobre e do imigrante rural adulto, como excluídos da escola. Di Pierro (2005) alerta que a EJA requer uma "questão de especificidade cultural", de modo que essas abstrações universalistas não se sustentem. Arroyo (2005), igualmente, trata as trajetórias de jovens e adultos como "trajetórias de coletivos".

Com o amplo movimento político de promoção dos direitos dos indivíduos com deficiência e do seu acesso ao ensino regular, esses sujeitos também passam a compor o coletivo da EJA. Esse grupo se caracteriza, especialmente, por pessoas cujo histórico escolar tem um registro de tempo de permanência significativo em Instituição de Educação Especial ou Classe Especial e, ainda, de fracasso na turma regular.

Pensar uma política pública para a EJA requer compreender essa identidade coletiva, refletindo sobre políticas afirmativas para esse coletivo de sujeitos, historica- 
mente negado, como fundamento e identidade da EJA. O próprio documento orientador das Diretrizes Curriculares Nacionais da EJA a define como a reparação de uma "dívida social" (Parecer no. 11/2000 CEB/CNE). Isso significa pensar pedagogicamente acerca de trajetórias humanas e escolares específicas, articulando os saberes sociais dos sujeitos aos escolares e rompendo com as práticas infantilizadas. Implica, também, reaver a função da EJA, que vem sendo reduzida ao espaço acolhedor de alunos com fracasso escolar, provenientes da escola regular. Portanto, essa modalidade, entendida como espaço de tempos humanos, tempo de juventude e de vida adulta, torna-se um lugar potente para a construção de significados acerca do mundo do trabalho e das demais experiências socioculturais vivenciadas pelos seus sujeitos. Constitui-se como desafio atual e emergente articular a EJA aos sujeitos da Educação Especial, a partir desse olhar.

\section{Jovens e adultos com deficiência e a (in)visibilidade na política de educação especial}

Os direcionamentos políticos da Educação Especial adotados pelo Ministério da Educação, ao longo de dez anos, trouxeram consigo mudanças no quadro de oferta de vagas na Educação Básica brasileira, expressando o caráter de dinamicidade que a área assume no contexto brasileiro atual.

Embora os indicadores numéricos do Censo Escolar da Educação Básica no Brasil (BRASIL, 2010; 2011) sejam contundentes, revelando, a cada ano, o aumento significativo de jovens e adultos com deficiência na EJA, cabe um olhar investigativo ao modo como tem sido construída a (in)visibilidade dos jovens e adultos com deficiência, nos atuais documentos normativos e orientadores da Política Nacional de Educação Especial, a esse grupo de sujeitos.

Tomam-se como parâmetros de análise o documento da Política de Educação Especial na perspectiva da Educação Inclusiva (2008); as Resoluções do Conselho Nacional de Educação, Res. n. 02/2001 CNE e Res. n. 04/2009 CNE; o Decreto Federal n. 7611/2011; bem como a instituição de programas intersetoriais, como o Benefício da Prestação Continuada na Escola, instituído mediante a Portaria Ministerial n. 18/2007, com o objetivo de apoiar a criação dos sistemas escolares inclusivos.

A aprovação da Política de Educação Especial na perspectiva da Educação Inclusiva, publicizada por meio da sistematização de um documento orientador, no ano de 2008, é resultado de uma intensa movimentação mundial a favor da perspectiva da Educação Inclusiva, fundamentada na concepção de direitos humanos. No capítulo II, no qual o documento aborda os marcos históricos e legais, citando os textos normativos atuais que embasam a promoção de uma política nacional de Educação Inclusiva, há referência à LDB n. 9394/1996. Sobre a referida lei, destaca o dispositivo da "terminalidade específica”, como medida pedagógica para aqueles que não atingirem o nível de escolarização necessário para conclusão do ensino fundamental, por ocasião de sua deficiência (art. 59 da Lei de Diretrizes e Bases da Educação Nacional 9394/96). Esse dispositivo ainda é causa de entendimentos diversos quanto à sua operacionalidade, de modo que, no contexto da prática, o que se tem observado são práticas pedagógicas 
empobrecidas com esses sujeitos, amparadas na possibilidade de certificar com terminalidade específica os alunos com deficiência que estão fora da faixa escolar.

No mesmo capítulo, o documento orientador refere-se ao papel da antiga Secretaria de Educação Especial (SEESP), atualmente incorporada pela SECADI, na promoção de ações afirmativas a favor do acesso e da permanência das pessoas com deficiência no ensino superior. Trata-se de preocupação legítima, mas que, por sua vez, atende apenas os jovens e adultos com deficiência que conseguem prosseguir em sua escolarização.

A política também faz referência ao programa de monitoramento escolar das pessoas com deficiência na faixa etária de 0 a 18 anos, a partir da criação do Benefício da Prestação Continuada (BPC) na Escola (2007). Portanto, ao aluno da Educação Básica, até 18 anos, há ações afirmativas que incentivam seu acesso à escola regular. Parece haver certa (in)visibilidade, no texto legal e normativo, do jovem e adulto com deficiência que não teve garantido o acesso e a permanência na escola quando infante, ou mesmo daquele que tem sua trajetória escolar marcada pelo fracasso. $\mathrm{O}$ capítulo IV, ao discorrer sobre os objetivos da Política Nacional de Educação Especial na perspectiva da Educação Inclusiva, mostra que o texto aponta, entre outras medidas, a necessidade da garantia da transversalidade da Educação Especial, desde a Educação Infantil até a Educação Superior; do Atendimento Educacional Especializado e da continuidade da escolarização nos níveis mais elevados de ensino.

Implementar a garantia da transversalidade da Educação Especial e o Atendimento Educacional Especializado, em todos os níveis de ensino, exige ações específicas, que contemplem os tempos pedagógicos de cada um dos níveis e modalidades de ensino que os sujeitos estejam cursando. No contexto da prática, o que percebemos é "o recorte e colagem" 3 de um modelo de Atendimento Educacional Especializado, pensado para os sujeitos que estão no Ensino Fundamental e Médio, para todos os sujeitos da Educação Infantil e da Educação de Jovens e Adultos. Estes dois últimos grupos são formados por sujeitos que, historicamente, vêm ficando à margem na implementação de políticas.

Sabe-se que, com a juvenilização da EJA, há hoje muitos jovens e adultos com deficiência na faixa etária dos 15 aos 18 anos incorporando o público-alvo da Educação Especial. A oferta do Atendimento Educacional Especializado, vinculada ao projeto pedagógico da Escola (e não como um apêndice, cuja oferta ocorre de modo assistemático ou esporádico, conforme a possibilidade de tempo do aluno jovem e adulto frequentar o turno oposto), poderia contribuir no sentido de ressignificar a sua experiência de adulto, propondo formas de participação social.

O documento orientador da Política Nacional de Educação Especial (2008) dirige-se aos alunos da EJA, explicitamente, apenas em um parágrafo, ao conceber o Atendimento Educacional Especializado:

Na modalidade da Educação de Jovens e Adultos e Educação Profissional, as ações da Educação Especial possibilitam a ampliação das oportunidades de escolarização, formação para ingresso no mundo do trabalho e efetiva participação social. (BRASIL, 2008, p. 22). 
A ausência de aprofundamento do texto normativo acerca desse público é percebida nas Resoluções que discorrem sobre as diretrizes curriculares da Educação Especial (Res. n. 02/2001 CNE/CEB) e nos dispositivos operacionais do Atendimento Educacional Especializado (Res. n. 04/2009 CNE/CEB), que deve ocorrer, prioritariamente, em turno inverso ao da escolarização, tendo, como dispositivo pedagógico e lócus principal, as Salas de Recursos Multifuncionais. É possível ler, na Res. n. 04/2009, artigo 5\%:

O Atendimento Educacional Especializado é realizado, prioritaria$m e n t e^{4}$, na sala de recursos multifuncionais da própria escola de ensino regular, no turno inverso da escolarização, não sendo substitutivo às classes comuns, podendo ser realizado também em Centros de Atendimento Educacional Especializado da rede pública ou de instituições comunitárias, filantrópicas, sem fins lucrativos, conveniadas com a Secretaria de Educação ou órgão equivalente dos Estados, Distrito Federal ou dos municípios. (BRASIL, 2008).

A legislação citada, ao sustentar a sala de recursos multifuncionais como espaço pedagógico prioritário para o atendimento, no turno inverso ao da escolarização, dá ênfase a essa configuração, mas não a nomeia como a única possível. Contudo, o acompanhamento das movimentações dos sistemas públicos escolares sugere que a leitura enrijecedora do texto legal, na proposição de uma única configuração ao Atendimento Educacional Especializado, vem prevalecendo, sendo recorrente a alegação de que o aluno da EJA com deficiência não tem tempo para frequentar a sala de recursos multifuncionais.

Ao considerarmos os desafios da EJA, seria necessário investir em uma reflexão acerca da diferenciação dos tempos pedagógicos da EJA em relação aos do ensino regular, de modo que se possam criar alternativas para a oferta do Atendimento Educacional Especializado, para além da sala de recursos multifuncionais. Cabe às gestões escolares repensar esse Atendimento para atender às especificidades desse público, ao invés de insistir no discurso de que o público não está adequado à proposta do Atendimento Educacional Especializado.

As preocupações que têm norteado a presente análise são compartilhadas por Campos e Duarte (2011), que, ao desenvolverem um estudo de caso sobre jovens e adultos com deficiência na EJA e a articulação com o Atendimento Educacional Especializado, em uma escola da rede municipal de uma cidade da região central do estado de São Paulo, constataram que a maioria dos alunos adultos com deficiência não podia frequentar esse atendimento no turno oposto, como prevê o texto legal, pois eram adultos com deficiência intelectual que trabalhavam durante o dia. As pesquisadoras fazem um alerta que se considera válido para a maioria dos estados brasileiros: "Inexiste a oferta de Atendimento Educacional Especializado no turno da noite das escolas regulares e, além disso, na Res. nº4/2009, não há nenhum artigo ou parágrafo que trate do Atendimento Educacional Especializado para estudantes com deficiência nas turmas de EJA" (CAMPOS e DUARTE, 2011, p. 280).

A (in)visibilidade desses sujeitos no texto normativo, de certo modo, contribui para a permanência de um quadro histórico de ensino de "segunda ordem" e de 
cunho compensatório, compactuando com a dupla exclusão dos jovens e adultos com deficiência. Se, de um lado, as políticas públicas da EJA têm dificuldade de reconhecer seus coletivos, a Educação Especial também precisa definir ações para esse público específico.

O mais recente Decreto n. 7611/2011, que dispõe sobre a Educação Especial e o Atendimento Educacional Especializado, define "a aprendizagem ao longo da vida" (art. $1^{\circ}$, inciso II) como dever do Estado dirigido aos alunos sujeitos da Educação Especial, pactuando com a concepção que, por sua vez, sustenta a discussão, em nível internacional, sobre a Educação de Jovens e Adultos. Esse texto também reforça o apoio financeiro às instituições especializadas privadas e filantrópicas que atuam na Educação Especial, como forma de corrigir uma dívida histórica de exclusão com os alunos que estão fora da faixa escolar, conforme texto da Nota Técnica n. 62/2011 $\mathrm{MEC} / \mathrm{SECADI} / \mathrm{DPEE}$, que traz orientações aos sistemas de ensino sobre o Decreto $n^{\circ} 7611 / 2011:$

O apoio financeiro às instituições especializadas mencionadas, referente ao atendimento de pessoas que não estão matriculadas no ensino regular, destina-se, especialmente, àquelas que se encontram fora da faixa etária de escolarização obrigatória, em razão de um processo histórico de exclusão escolar. (BRASIL, 2011).

A constatação feita pelo texto da lei anuncia uma lacuna em relação a esse grupo de sujeitos, com o qual a sociedade tem uma "dívida histórica", e exige que, em longo prazo, sejam construídas alternativas intersetoriais efetivas, para a promoção da aprendizagem ao longo da vida, para todos, em qualquer tempo e idade.

A forma discreta como se constrói, nos textos normativos, a participação da Educação Especial na EJA também é retratada na ausência de documentos subsidiários produzidos pelo $\mathrm{MEC}$, articulando as duas áreas.

Considera-se que aquilo que foi designado como (in)visibilidade relativa ao público da EJA, nos documentos normativos e orientadores da política brasileira relativa à Educação Especial, não inviabiliza a criação de estratégias e de novas configurações possíveis a esses alunos, afinal, a política em ação independe apenas do texto normativo, mas constrói-se a partir dos contextos desafiadores da prática.

\section{A presença da educação especial nos fóruns de EJA}

Os Fóruns de EJA, ao longo da história política nacional, consolidaram-se como espaços articuladores de políticas educacionais para jovens e adultos, resultando na ampliação das responsabilidades do Estado e corrigindo uma história calcada no assistencialismo, o que justifica o investimento da pesquisa exploratória nessa instância. Atualmente, todos os 27 estados participam dos Fóruns, espaços de diálogo que se tornaram facilitados pelo auge das tecnologias, a partir do portal virtual dos Fóruns.

Rastreando os 12 relatórios-síntese dos Encontros Nacionais de Educação de Jovens e Adultos (ENEJA), promovidos pelo Fórum Nacional de EJA, em parceria com os Fóruns Estaduais, anualmente, desde o ano de 1999 até 2011, é possível cons- 
tatar o modo como se insere a temática da Educação Especial, sendo retomada, a cada ano, nos relatórios, com mais ênfase. De todos eles, apenas nos relatórios-síntese de 1999 (I ENEJA-RJ) e de 2001 (III ENEJA-SP) não há menção explícita aos sujeitos com deficiência, embora as discussões da atenção à diversidade estejam presentes em todos eles. A incorporação dos direcionamentos políticos da Educação Inclusiva pode ser percebida nos relatórios, com a alteração de terminologias, tais como a substituição da expressão portador de necessidades especiais por pessoas com necessidades educativas especiais (VII ENEJA-GO, 2005; VIII ENEJA-PE, 2006). Também, a partir de 2008, a expressão Educação Inclusiva torna-se presente. A demanda da formação de professores para atender esse público aparece expressivamente a partir de 2005, repetindo-se nos relatórios subsequentes.

No relatório-síntese de 2008 (X ENEJA-RJ), o assunto "EJA e Educação Inclusiva" aparece como uma das temáticas que devem compor o Fórum EJA e suas especificidades. Apesar da reincidência dessa temática, reafirmando a necessidade de estudo e reflexão sobre práticas pedagógicas envolvendo o público com deficiência na EJA em praticamente todos os relatórios, também é possível observar alguns movimentos de rupturas e descontinuidades. No relatório de 2009 (XI ENEJA-PA), por exemplo, a discussão volta a aparecer, de modo geral, relacionada ao termo diversidade.

Como se percebe, embora a discussão sobre as pessoas com deficiência na Educação de Jovens e Adultos apareça diluída nos diversos momentos sistemáticos do Fórum EJA, ainda ocupa lugar bastante discreto. Analisando as produções científicas resultantes dos três Seminários Nacionais de Formação de Educadores de Jovens e Adultos, também disponíveis no Fórum EJA, apenas no terceiro seminário, realizado em 2010, em Porto Alegre, houve uma mesa temática direcionada à discussão sobre as pessoas com deficiência na Educação de Jovens e Adultos, na qual apenas o trabalho de uma pesquisadora foi apresentado, enquanto, nas demais mesas, houve participações de mais pesquisadores, garantindo a pluralidade do debate.

\section{A aproximação entre a educação de jovens e adultos e a educação especial nas pesquisas}

Nesse item, apresenta-se a análise das produções encontradas no portal de busca da CAPES, Teses e Dissertações, e nos Grupos de Trabalho 15 - Educação Especial e 18 - Educação de Jovens e Adultos da Associação Nacional de Pesquisadores de Pós-Graduação em Educação - ANPEd.

Destaca-se, após busca no Banco de Dados de Teses e Dissertações da CAPES, que as discussões acadêmicas acerca dessa temática ainda são quantitativamente modestas. A maior parte dos trabalhos trata dos sujeitos com deficiência mental (FONSECA, 2003; MAFEZZOLI, 2004; DANTAS, 2006; XAVIER, 2007). Pensase que a história de institucionalização desse grupo específico de sujeitos nas instituições de educação especial seja um tema provocativo. Além disso, ressalta-se o desafio de articular espaços educativos para esses sujeitos, reconhecidos como incapazes de aprender. Ainda, sobre o interesse em pesquisar grupos de sujeitos específicos, cita-se o trabalho de Cirino (2007) sobre a educação dos jovens e adultos com deficiência visual. 
Os trabalhos privilegiam como lócus de pesquisa tanto a Escola Regular como a Escola Especial, procurando compreender as possibilidades de os sujeitos com deficiência estabelecerem uma interlocução, em ambos os espaços, tendo como referência a construção de vínculos sociais e de aprendizagem. A maior parte das pesquisas denuncia a ausência de políticas públicas adequadas para garantir a efetivação da Educação de Jovens e Adultos das pessoas com deficiência como direito social (BRUNO, 2006; FONSECA, 2003; CIRINO, 2007; TINÓS, 2010; FREITAS, 2010). Em contrapartida à denúncia dessa ausência, as pesquisas consideram a necessidade da promoção de apoios pedagógicos específicos para a inclusão dos jovens e adultos com deficiência e a qualificação pedagógica dos professores e gestores como condição imprescindivel para que isso aconteça.

Em trabalho que resgata algumas pesquisas sobre a interface entre a Educação de Jovens e Adultos e a Educação Especial, Siems (2010) discorre sobre o silenciamento de pesquisas que abordam a formação do docente que atua com jovens e adultos com deficiência, denunciando um processo de "desprofissionalização da docência", verificada tanto na Educação Especial como na Educação de Jovens e Adultos.

Com relação às produções da ANPEd., houve a atenção dirigida, em um primeiro momento, à identificação quantitativa do número de trabalhos envolvendo os sujeitos jovens e adultos com deficiência, apresentados nos GT-15 (Educação Especial) e GT-18 (Educação de Pessoas Jovens e Adultas), de 2000 a 2012.

Os indicadores numéricos expressam a participação discreta de pesquisas envolvendo os jovens e adultos com deficiência, tanto no GT-15 como no GT-18. No GT da Educação Especial, é possível constatar, a cada ano, uma articulação crescente da área, de modo que, nos últimos três anos, o número de trabalhos apresentados mantém-se superior a vinte. As temáticas são diversas, envolvendo grupos de sujeitos com características específicas e seus processos de identificação; práticas pedagógicas; formação de professores e o Atendimento Educacional Especializado na perspectiva da Educação Inclusiva. Prevalece o olhar voltado à Educação Básica, especificamente, à etapa do Ensino Fundamental. De modo tímido, são apresentadas pesquisas envolvendo os sujeitos da Educação Infantil e, com visibilidade ainda menor, os jovens e adultos com deficiência.

Os números evidenciam que de 232 trabalhos apresentados no GT-15, Educação Especial, no espaço de tempo que vai de 2000 a 2012, apenas 17 trabalhos enfocam os jovens e adultos com deficiência, ou seja, 7,3\% dos trabalhos apresentados em mais de dez anos de socialização de pesquisas. Esse número é ainda menor se considerarmos as pesquisas que tratam dos jovens e adultos com deficiência no espaço da escola comum.

Com relação ao GT-18, Educação de Pessoas Jovens e Adultas, é ainda mais acentuada a invisibilidade dos sujeitos com deficiência nas pesquisas. De 216 pesquisas apresentadas, no intervalo de 2000-2012, apenas um trabalho enfoca os jovens e adultos com deficiência, ou seja, $0,5 \%$ do total das pesquisas. 
Um balanço da produção do GT - Educação de Pessoas Jovens e Adultas, no período de 1998 a 2008, realizado por Ventura (2009) e exposto na 32a Reunião Anual da ANPED (2009), destaca que se avolumam as pesquisas com enfoque nas políticas de EJA e nas etapas iniciais de escolarização, "predominando a identificação da EJA como oferta educativa alfabetizadora" (VENTURA, 2009, p. 2). A autora faz a seguinte ressalva: “... chama a atenção o fato de o GT 18, apesar de suscetível à influência das proposições da educação ao longo da vida e da diversidade de sujeitos, não ter se constituído como um espaço de discussão privilegiado de tais questões" (VENTURA, 2009, p. 13).

Com relação às temáticas que constituem as 18 pesquisas envolvendo os jovens e adultos com deficiência, foi possível distinguir três eixos norteadores: pesquisas sobre jovens e adultos com deficiência, métodos narrativos/protagonismo da pessoa com deficiência (07 pesquisas no GT-15); interface entre a Educação Especial e a de Educação de Jovens e Adultos (01 pesquisa no GT-18); Jovens e Adultos com deficiência e temáticas diversas (10 pesquisas no GT-15).

Apenas um trabalho enfoca a necessidade de interface e comunicação entre as áreas da Educação Especial e da Educação de Jovens e Adultos, reconhecendo a migração expressiva dos jovens com deficiência das instituições especializadas para a modalidade da EJA (VARELLA, 2011).

Considerando o Banco de Dissertações e Teses da Capes como uma das principais fontes aglutinantes das produções acadêmicas, assim como o papel da Associação Nacional de Pesquisadores em Pós-Graduação, como espaço de socialização das principais pesquisas realizadas no âmbito da universidade, pensa-se ser significativo o número reduzido de pesquisas encontradas nessas fontes, envolvendo os jovens e adultos com deficiência. A análise da relação entre uma problemática educacional e sua presença na pesquisa acadêmica propõe como desafio estabelecer mecanismos capazes de conceber a Educação de Jovens e Adultos para todos os seus sujeitos, inclusive para as pessoas com deficiência.

\section{Questões que permanecem questões}

Em linhas gerais, se reconhece que os processos de escolarização dos jovens e adultos com deficiência, na escola regular, não têm prevalecido como interesse central das políticas públicas educacionais. Esse silenciamento ou essa aparente (in)visibilidade dos jovens e adultos com deficiência, nos documentos normativos das políticas públicas da Educação Especial e da EJA, nas produções acadêmicas e nas sistematizações decorrentes da mobilização social organizada, a partir do Fórum Nacional de EJA, abre uma lacuna ou um espaço possível de ser preenchido por visões reducionistas sobre esse grupo de sujeitos. Afinal, tudo aquilo que não é refletido e problematizado tem uma tendência a se manter da mesma forma. No caso dos jovens e adultos com deficiência, a invisibilidade de ações para incluí-los nos processos escolares do ensino comum pode significar a permanência desses sujeitos nos espaços especializados ou, mesmo quando há o deslocamento para o ensino comum, pode significar a manutenção da mesma configuração ou forma segregadora. 
Além disso, o estudo aponta para as questões que permanecem questões e reafirmam a (re)invenção da necessária articulação entre as duas áreas: as configurações do Atendimento Educacional Especializado para o jovem e adulto com deficiência que frequenta a EJA e o investimento em práticas pedagógicas que acolham os modos e os tempos de aprendizagem de cada sujeito.

\section{Referências}

ARROYO, M. G. Educação de jovens-adultos: um campo de direitos e de responsabilidade pública. In: SOARES, L.; GIOVANETTI, M. A.; GOMES, N. L. Diálogos na educação de jovens e adultos. Minas Gerais: Autêntica, 2005. p. 19-50.

ASSOCIAÇÃO NACIONAL DE PESQUISADORES EM PÓS-GRADUAÇÃO. Reuniões Anuais. Trabalhos completos e Pôsteres GT 15 e GT 18. <site> Disponível em: <http:// anped.org.br >. Acesso em: 25 nov. 2012.

BRASIL. MEC. INEP. LDBEN 9394/96 que estabelece as Diretrizes e bases da Educação Nacional. Brasília, 1996.

MEC. SECADI. DPEE. Nota Técnica n. 62/2011. Orientações aos Sistemas de Ensino sobre o Decreto no 7.611/2011. Brasília, 08 de dezembro de 2011. sília, 2008.

. MEC. SEESP. Política nacional de Educação Especial na perspectiva inclusiva. Bra-

. Ministério da Educação. Conselho Nacional de Educação. Câmara de Educação Básica. Resolução n. 2, de 11 de setembro de 2001. Diretrizes Nacionais para a Educação Especial na Educação Básica. Brasília, 2001.

BRASIL. Ministério da Educação. Conselho Nacional de Educação. Câmara de Educação Básica. Resolução n. 4, de 2 de outubro de 2009. Institui Diretrizes Operacionais para o Atendimento Educacional Especializado na Educação Básica, modalidade Educação Especial, 2009.

Ministério da Educação. Conselho Nacional de Educação. Câmara da Educação Básica.

Parecer n. 11 de maio de 2000. Diretrizes Curriculares Nacionais para a Educação de Jovens e Adultos. Brasília, 2000

Ministério da Educação. Instituto Nacional de Estudos e Pesquisas Educacionais Anísio Teixeira. Resumo técnico Censo Escolar 2010. Brasília, 2010.

Ministério da Educação. Instituto Nacional de Estudos e Pesquisas Educacionais Anísio Teixeira. Resumo técnico Censo Escolar 2011. Brasília, 2011.

Ministério da Educação. Portaria Normativa Interministerial n. 18, de 24 de abril de 2007. Brasília, 2007.

. Presidência da República. Casa Civil. Decreto 7611, de 17 de novembro de 2011. Dispõe sobre a Educação Especial, o Atendimento Educacional Especializado e dá outras providências. Brasília, 2011.

BRUNO, A. G. G. Interdições e contradições na política de inclusão de jovens e adultos com deficiência no Estado de Mato Grosso do Sul. 2006. Dissertação (Mestrado) - Campo Grande, Universidade Federal de Mato Grosso do Sul, 2006.

CAMPOS, J. A. de P. P.; DUARTE, M. O aluno com deficiência na EJA: reflexões sobre o atendimento educacional especializado a partir do relato de uma professora de educação especial. Revista Educação Especial. Santa Maria, v. 24, n. 40, p. 271-284, maio/ago. de 2011. Disponível em: <http://www.ufsm.br/revisstaeducacaoespecial>. Acesso em: 10 set. 2012. 
CIRINO, R. M. B. Concepções de jovens e adultos com deficiência visual sobre os contextos de aprendizagem escolar. 2007. Dissertação (Mestrado) - Curitiba: Universidade Federal do Paraná, 2007.

DANTAS, D. de C. L.Jovens e adultos com deficiência mental: entre o limite e possibilidades de permanência na escola regular, em tempos de inclusão. 2006. Dissertação (Mestrado) - Natal: Universidade Federal do Rio Grande do Norte, 2006.

DI PIERRO, M. C. Notas sobre a redefinição da identidade e das políticas públicas e de Educação de Jovens e Adultos no Brasil. SP: Campinas. Educação \& Sociedade, v. 26, n. 92, p. 1115-1139, Especial; Outubro de 2005. Disponível em: <http//cedes.unicamp.br>. Acesso em: 23 set. 2012

FONSECA, M. V. de A. Versões e inversões: a educação de jovens e adultos com deficiência mental. 2003. Dissertação (Mestrado) - Campo Grande: UFMS, 2003.

FÓRUM nacional de EJA. Encontros nacionais de EJA. I ENEJA, Rio de Janeiro, 1999. III ENEJA, São Paulo, 2001; VII ENEJA, Goiás, 2005; VIII ENEJA, Pernambuco, 2006; X ENEJA, Rio de Janeiro, 2008; XI ENEJA, Pará, 2009. Disponível em: <htpp://www.forumeja. org.br/encontrosnacionaiseja>. Acesso em: 23 set. 2012.

Seminários nacionais de formação de educadores em EJA. III SNF, Porto Alegre, 2009. Disponível em: <http//www.forumeja.org.br/node/2283>. Acesso em: 23 set. 2012.

FREITAS, A. P. R. A educação escolar de jovens e adultos com deficiência: do direito conquistado à luta por sua efetivação. 2010. Dissertação (Mestrado) - São Paulo: USP, 2010.

MAFEZZOLI, R. R. Olha, eu já cresci: a infantilização de jovens e adultos com deficiência mental. Dissertação (Mestrado), Piracicaba: Universidade Metodista de Piracicaba, 2004.

SIEMS, M. E. R. Educação de jovens e adultos com deficiência: caminhos em construção. In: Educação de Jovens e Adultos: Trabalhos premiados ANPED. Educação em Foco. Juiz de Fora: UFJF, v. 16, n. 2, set. 2011/fev., 2012.p. 61-79.

TEZZARI, M.; BAPTISTA, C. R. A medicina como origem e a pedagogia como meta da ação docente na educação especial. In: CAIADO, K. R.; JESUS, D. de M.; BAPTISTA, C. R. (org.) Professores e educação especial formação em foco. Porto Alegre: Mediação, 2011. v. 1. p. 19-34.

TINÓS, L. M. S. Caminhos de alunos com deficiências à Educação de Jovens e Adultos: conhecendo e compreendendo histórias escolares. 2010. Dissertação (Mestrado) - São Paulo: Universidade Federal de São Carlos, 2010.

VARELLA,M. da C. B. EJA e Educação Especial: caminhos que se cruzam. Anais... 34a Reunião Anual da ANPED, Natal, 2011.

VENTURA, J. P. A política educacional para a EJA na produção científica do GT Educação de Pessoas Jovens e Adultas da ANPED (1998-2008): contribuições para o debate. Anais... 32a Reunião Anual da ANPED, Caxambu, 2009. p. 1-15.

XAVIER, D. R. Possibilidades dialógicas e interações sociais de jovens e adultos com deficiência mental no contexto da educação especial. 2007. Dissertação (Mestrado), Piracicaba: Universidade Metodista de Piracicaba, 2007. 


\section{Notas}

${ }^{1} \mathrm{O}$ termo idiotia refere-se ao modo de nomear as pessoas com deficiência no contexto histórico em que viveu Séguin.

${ }^{2}$ Desde 2010, o governo federal estabeleceu nova configuração à Secretaria de Educação Especial - SEESP, incorporando-a à Secretaria de Educação Continuada, Alfabetização, Diversidade e Inclusão - SECADI.

${ }^{3}$ A percepção do Atendimento Educacional Especializado ao jovem e adulto com deficiência como "recorte e colagem", no contexto deste estudo, é resultante das análises construídas na seguinte pesquisa de mestrado em Educação: HAAS, Clarissa. Narrativas e percursos escolares de jovens e adultos com deficiência: "Isso me lembra uma história!". Porto Alegre: UFRGS, 2013, 214f. Dissertação (Mestrado em Educação). Programa de Pós-Graduação em Educação, Faculdade de Educação, Universidade Federal do Rio Grande do Sul, Porto Alegre, 2013.

${ }^{4}$ Grifo meu.

* Doutoranda em Educação pela Universidade Federal do Rio Grande do Sul, Porto Alegre, Rio Grande do Sul, Brasil.

\section{Correspondência}

Clarissa Haas - Universidade Federal do Rio Grande do Sul, Faculdade de Educação. Avenida Paula Gama, s\n, Faculdade de Educação, prédio 12201, UFRGS, Campus Central Farroupilha. CEP: 90046-900 - Porto Alegre, Rio Grande do Sul, Brasil.

E-mail:cla.haas@hotmail.com

Recebido em 26 de maio de 2013

Aprovado em 20 de fevereiro de 2014 